\title{
DWT Based Deflection Optimization in Deck Slab with Free Vibration Analysis Nikhil Agrawal ${ }^{a} *$, Dr. Rajeev Chandak ${ }^{b}$ \\ ${ }^{a}$ M. E. Scholar, Department of Civil Engineering, Jabalpur Engineering College, Jabalpur, Madhya Pradesh, India \\ brofessor, Department of Civil Engineering, Jabalpur Engineering College, Jabalpur, Madhya Pradesh, India \\ *Corresponding e-mail: nikhilag1995@gmail.com
}

\section{ABSTRACT}

Article Info

Volume 8, Issue 6

Page Number : 285-291

\section{Publication Issue}

November-December-2021

Article History

Accepted : 20 Nov 2021

Published : 05 Dec 2021
This review presents several types of deck slab technologies that have appeared over the last 20 years. The slab is a reinforced concrete slab that can reduce the amount (volume) of voided concrete. However, it has only been used in one way and must be supported by a beam and / or a fixed wall. The idea was to make a deck slab two-axis slab with the same function as a solid slab, but the weight was significantly reduced due to excessive concrete removal.

Keywords : Span/Depth Ratio, Deck slab, IRC Loading, Staad pro.

\section{INTRODUCTION}

Development of arching (or compressive membrane) action in conventionally reinforced concrete (RC) beams or slabs with external end or edge restraints can significantly increase stiffness and ultimate strength of the members that in turn can improve structural efficiency and performance of the RC frames, slabs and culverts under static, cyclic and extreme loading conditions [1-9]. In addition to concrete members with reinforcing bars, development of arching action can significantly improve the peak load carrying capacity and fatigue life of the fibre reinforced concrete beams and slabs $[10,11]$. Various aspects of the development of arching action and its beneficial effects particularly in $\mathrm{RC}$ deck slabs and culverts have been investigated experimentally and numerically over the past few decades [8,10,12-14]. The strength enhancement provided by the arching action has been also utilised to develop the concept of transversely confined steel free bridge decks $[1,15]$. In particular, the steel free decks taking advantage of polymeric fibres/bars in lieu of steel bars have been used to resolve the issues associated with corrosion of the internal reinforcing steel bars and to improve the durability, serviceability and longevity of bridge decks $[3,16]$. The concept of steel free decks has been also adopted to develop durable rehabilitation strategies for existing RC bridge decks under traffic load [15]. In addition, some bridge design codes recognise the reserve of strength provided by the arching action under ultimate limit state conditions and allow replacing the conventional reinforcing steel bars with external confining systems (in the transverse direction) that mobilise arching 
action and provide ultimate load capacity comparable to that of conventionally reinforced concrete slabs $[8,9]$. The transverse confining system usually comprises of ties/straps welded on the top flange of the steel girders and partially embedded in the concrete haunch that separates the slab from the top flange of the steel girders.

\section{INDIAN SCENARIO}

Bridges may be of Reinforced concrete or steel construction. Reinforced concrete is well suited for the construction of highway bridges in the small and medium span range. Their durability, rigidity, economy and ease with which pleasing appearance can be obtained make them suitable for this purpose. The usual types of reinforced concrete bridges are slab bridges, Girder and slab(T-beam) bridges, Hollow girder bridges, Balanced cantilever bridges, Rigid frame bridges, Arch bridges, Bow string girder bridges. In INDIA Bridges for road are designed as per the recommendations of the Indian Roads congress (I.R.C). This code classifies bridges and culverts into the I.R.C class A loading, I.R.C class AA loading wheeled vehicle I.R.C class AA loading tracked vehicle and I.R.C class B loading. Apart from these loadings other loads considered are Dead load of structure, Impact load, wind load, longitudinal forces, seismic load, Temperature effect, Settlement, secondary, erection, Centrifugal force, Earth pressure, Drag and tractive force. Flyover is a super structure providing passage of vehicles over an existing road to avoid the unnecessary intersections. Flyovers are also called Road bridges.

\section{LITERATURE REVIEW}

LifeiZhang, "Structural performance evaluation of ECC link slabs reinforced with FRP bars for jointless bridge decks": Deterioration of traditional mechanical expansion joints significantly affects the durability of bridge structures. Engineered cementitious composites have been proposed as an alternative to expansion joints in bridge decks. ECC link slabs were cast and tested under monotonic cyclic loading. Link slabs, reinforced with fibre-reinforced polymer bars, demonstrated sufficient flexibility to meet the current design protocols. Nonlinear finite element models were constructed based on the experimental data. Depth-span ratio and reinforcement ratio of such link slabs must not exceed 0.12 and $0.72 \%$. Link slab debonded length should be larger than $0.8 \%$ to obtain low bending stiffness.

MinghongQiu, "Flexural behavior of UHPC joints for precast UHPC deck slabs": This study aims to experimentally investigate the flexural behavior of ultra-high-performance concrete (UHPC) joint connection for precast UHPC deck slabs. Twelve fullscale jointed UHPC deck slabs were tested and discussed with respect to their failure modes, loaddisplacement response, ductile behavior, and cracking characteristics. The experimental variables included shape of the joint connection, steel reinforcement diameter, restraining condition of the precast UHPC slab, and joint interface roughness. The experimental results showed that all specimens exhibited a flexural failure with yielding of steel reinforcement, local UHPC crushing at the top surface, and excessive opening of the flexural crack, but exhibited varying locations of the critical crack between the tests. In comparison to the integral casting detail, the rectangular joint had a lower cracking resistance, post-cracking stiffness, and flexural capacity as well as higher ductility, whereas the T-shaped joint led to a relatively higher cracking resistance, stiffness, and flexural capacity as well as lower ductility. Both joint shapes showed little influence on the specimens' precracking stiffness. In addition, increasing the steel reinforcement diameter not only improved the flexural capacity of the UHPC joint connection but also improved the cracking resistance (including the cracking load, the load at the crack width of $0.05 \mathrm{~mm}$, and the crack width propagation rate). Moreover, the mechanical performance of the jointed UHPC slabs 
with different restraining conditions in the precast UHPC slab was similar. Furthermore, improving the interface roughness at the precast UHPC slab is in favor of increasing the cracking resistance, but played little effect on other mechanical characteristics. The present main outcomes might provide a reference for future flexural design on the precast UHPC deck slab with the UHPC joint connection.

J.Díaz, "A computer code for finite element analysis and design of post-tensioned voided slab bridge decks with orthotropic behavior": This paper presents a computer software which allows the generation of a complete structural model of a concrete bridge with a voided slab deck, a common design for medium span bridges. The code implements the orthotropic plate paradigm and provides a graphical user interface, which allows both preprocessing and post-processing, linked to a commercial finite element package. A description of the code is presented, along with the formulation of the orthotropic plate. Verification and comparison examples demonstrate the performance and features of the software and also the applicability of the formulation.

Fabricio L.Bolina, "Experimental analysis on the structural continuity effect in steel decking concrete slabs subjected to fire": Composite steel decking concrete slabs are an important structural member in building construction. Nevertheless, the behavior of these slabs in case of fire are not yet well characterized and the corresponding fire design methods need improvements. Several parameters that affect the behavior of these slabs in case of fire and that are not taken into account in the fire design at the moment have to be included. One of these parameters, is the continuity effect between slab panels. This study evaluated the structural performance of continuous steel decking concrete slabs subjected to fire.

IsamuYoshitake, "Moving-wheel fatigue durability of cantilever bridge deck slab strengthened with high- modulus CFRP rods": Reinforced concrete (RC) slabs of highway bridge decks are gradually deteriorated due to the traffic vehicle wheel-loading. Fatigue is one of a number of possible causes for the deterioration. Cantilever RC slabs of the bridge are also damaged by fatigue loading. To increase the fatigue durability of the bridge deck slab, the nearsurface mounted (NSM) technique is used with carbon fiber reinforced polymer (CFRP) rods embedded in the RC slab as an effective strengthening method. This study presents the fatigue characteristics of cantilever RC slabs strengthened with CFRP rods with a high-modulus of elasticity. A cantilever RC slab specimen with embedded CFRP rods with high moduli was constructed on a movingwheel load testing machine and tested for approximately 11 months. The slab had a minimum thickness of $160 \mathrm{~mm}$ (as stipulated by the Japanese design code), and the minimum number of steel reinforcements was embedded to ensure (negative) flexural failure of the RC slab where CFRP rods were not used. During the test, the CFRP strengthened slab specimen was subjected to a negative bending moment from repeated moving-wheel loads. Very limited experimental data are available for the evaluation of the structural behavior of cantilever bridge decks subjected to wheel loads.

MohamedAdel, "Early damage detection of fatigue failure for RC deck slabs under wheel load moving test using image analysis with artificial intelligence": Reinforced concrete (RC) bridge decks suffer from cracking damages caused by traffic loading and environmental-related defects, such as the alkalisilica reaction (ASR). These require inspections involving measuring crack width and density followed by essential maintenance and repair works, however, there are no signs for fatigue failure. In this study, the out-of-plane shear deformations which cause small delaminations (pits) along surface cracks are proposed as an early indicator for fatigue failure. Thus, un-damaged and ASR-damaged RC deck slabs 
are tested under moving wheel loading and, using image-recognition for surface cracks detection, the pits along surface cracks are captured using an artificial intelligence (AI) model. The results show that, while both crack and pit density increase over the fatigue life of un-damaged slabs, there is an earlier sudden increase in pit density.

AntonBogdanić, "Numerical and experimental investigation of anchor channels subjected to shear load in composite slabs with profiled steel decking": Anchor channels are a type of cast-in place anchor that are well suited for supporting curtain walls and other applications in commercial construction because they provide flexibility when positioning a fixture. For curtain wall applications, anchor channels are often installed close to the edge of a floor slab. Modern high-rise buildings commonly use composite slabs consisting of profiled steel decking with an insitu cast concrete topping. The specific geometry of the composite slab is a major factor to consider when designing anchor channel connections.

DaXiang, "Fatigue behavior and failure mechanism of steel-concrete composite deck slabs with perforated ribs, Engineering Structures": This paper aims at investigating the variable-amplitude fatigue behavior and failure mechanism of the steel-concrete composite (SCC) deck slab with perforated ribs. Firstly, two identical full-scale specimens were tested under different fatigue loading procedures. Test results reveal that the fatigue failure process starts with the initiation of cracks at the welding part between the steel plate and perforated rib, after which the slab could sustain tens or hundreds of thousands of load cycles until the crushing of concrete. As load amplitude increases by $54 \%$, the crack propagation rate is accelerated by $300 \%$, and the fatigue life from the crack initiation to the crushing of concrete is reduced by $79 \%$. Higher load amplitude applied in the earlier service stage leads to the irreversible and a higher level of degradation on the stiffness, deformation recovery, and composite action.

FabricioBolina, "Thermal analysis of steel decking concrete slabs in case of fire": The thermal behavior of composite steel-concrete slabs in fire is more or less known, however there are still a lot of different aspects in the fire design methods that need clarification. A comparison of the temperature distribution in the cross-section of steel decking concrete slabs subjected to fire is made through three different procedures: (a) experimental, (b) numerical and (c) analytical methods. The experimental tests corresponding to eight real-scale fire tests on slabs carried out by the authors. These tests have been used to calibrate numerical models for being used with the finite element software Abaqus. The analytical methods were the ones proposed in Annex D of EN 1994-1-2.

OuYi, "Performance of crumb rubber concrete composite-deck slabs in 4-point-bending, Journal of Building Engineering": A composite slab reinforced by profiled steel deck is a structural system where the longitudinal shear resistance between the steel deck and the concrete is the critical factor that governs the member capacity of the slabs under shear and/or flexural loads. Partially replacing concrete sand by crumbed rubber particles derived from used tyres to form crumb rubber concrete (CRC) can adversely affect the concrete mechanical characteristics; however, the plastic energy absorption and ductility of CRC have been shown to be improved. This paper presents an experimental study of large-scale composite slabs made of CRC or conventional concrete (CC) at similar compressive strength of $25 \mathrm{MPa}$ that were tested under 4-point bending. Different shear spans and loading schemes were applied and tested in this study. The slabs were all $130 \mathrm{~mm}$ thick and had $3400 \mathrm{~mm}$ full span $(800 \mathrm{~mm}$ shear span) for long slabs and $1800 \mathrm{~mm}$ full span (400 mm shear span) for short slabs. The overall 
performances, load carrying capacity, end-slippage, and interaction with steel of the tested CRC slabs were comparable or even better than those of the

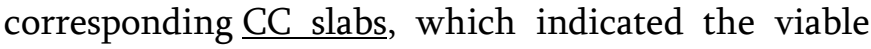
substitution of CRC in composite slabs.

Alex M.D.de Sousa, "Extended CSDT model for shear capacity assessments of bridge deck slabs, Engineering Structures": The shear strength evaluation of reinforced concrete bridge deck slabs by accurate models can indicate strength reserves and avoid costly operations necessary for the extension of their lifetime. This article introduces an approach that extends the Critical Shear Displacement Theory model (CSDT) for reaching higher levels of approximation of the shear strength for slabs subjected to concentrated loads close to the support.

Rajai Z.Al-Rousan, "Nonlinear finite element analysis of full-scale concrete bridge deck slabs reinforced with FRP bars": Bridges with reinforced concrete deck slabs are more vulnerable to environmentalinduced deterioration mainly due to corrosion. Carbon and glass fiber reinforced polymer (FRP) bars are getting attention as an alternative to steel bars to enhance the overall performance of the concrete bridge deck slabs and minimize corrosion-induced deteriorations.

P.Arezoomand Langarudi, "Numerical study of the behavior of bolted shear connectors in composite slabs with steel deck": Nowadays, conventional shear connectors used in the composite slab with steel deck are welded headed shear studs. If the structure reaches the end of its design life, repairing these connectors will cost a lot and cause significant environmental damage. In this paper, with a numerical study, welded shear stud connectors were replaced with new bolted shear ones and the effects of parameters, such as: concrete strength, different positions, heights and diameters of the shear connectors, and the type and thickness of the steel deck, as well as the effect of the reinforcement arrangement on the behavior of these connectors, are evaluated. Moreover, various failure modes are investigated and the results are compared to AISC equations provided for welded shear connectors, to calculate the shear capacity of new bolted connectors. The results show that these connectors could be a good alternative to welded shear studs.

Ying-JieZhu, "Novel design method for reinforced concrete decks in composite girders considering compressive membrane action": The deck slab in composite box girder is laterally and rotationally restrained, and the compressive membrane action (CMA) improves the stiffness and capacity of the slab under the vertical load. However, a rational design method for the slab in composite box girder is still lacking. The purpose of this paper is to establish theoretical models to predict the behaviors of the laterally and rotationally restrained slab at ultimate and serviceability limit states. First, a nonlinear whole process mechanism analysis of a laterally and rotationally restrained deck slab is conducted. Compared with previous studies, this research considers additional factors such as the rotational restraint stiffness, the lateral restraint eccentricity, two lateral restraints and the thickness variation of the deck slab.

YuZheng, "Investigation of the behaviour of SCC bridge deck slabs reinforced with BFRP bars under concentrated loads": Self-compacting concrete (SCC) with high-volume industrial wastes, such as fly-ash, reinforced with fibre-reinforced polymer (FRP) bars is anticipated to address the concerns on the usage of traditional reinforced concrete structures, such as corrosion of internal steel reinforcement, costly repair and development to low-carbon footprint infrastructures.

\section{CONCLUSION}

A conclusion section is not required. Although a conclusion may review the main points of the paper, do not replicate the abstract as the conclusion. A 
conclusion might elaborate on the importance of the work or suggest applications and extensions. Flyovers are common in big cities to reduce the traffic congestions. The design of a deck slab for a Reinforced

Concrete Bridge as per the bridge code IRC 21- 1987 with analysis for dynamic response due to moving loads is illustrated.

\section{CONCLUSION}

Based on the results of the study, the conclusions of this study are as follows:

1. Brand Image has a significant positive effect on repurchase. The higher the brand image, there will be an increase in repurchase at Kopi Petani Nusantara.

2. The price of the product has a significant positive effect on repeat purchases. The higher the benefits of product prices owned by employees, there will be the increase in repurchasing at Kopi Petani Nusantara.

3. Product quality has a significant positive effect on repeat purchases. The higher the quality possessed by employees, there will be increased in repurchase at Kopi Petani Nusantara.

4. Simultaneously, brand image, product price, product quality have a significant effect on repurchasing at Kopi Petani Nusantara.

\section{REFERENCES}

[1]. LifeiZhang, "Structural performance evaluation of ECC link slabs reinforced with FRP bars for jointless bridge decks", Construction and Building Materials, Volume 304, 18 October 2021, 124462.

[2]. MinghongQiu, "Flexural behavior of UHPC joints for precast UHPC deck slabs",
Engineering Structures, Volume 251, Part A, 15 January 2022, 113422

[3]. J.Díaz, "A computer code for finite element analysis and design of post-tensioned voided slab bridge decks with orthotropic behavior", Advances in Engineering Software, Volume 41, Issues 7-8, July-August 2010, Pages 987-999.

[4]. Fabricio L.Bolina, "Experimental analysis on the structural continuity effect in steel decking concrete slabs subjected to fire", Engineering Structures, Volume 240, 1 August 2021, 112299

[5]. IsamuYoshitake, "Moving-wheel fatigue durability of cantilever bridge deck slab strengthened with high-modulus CFRP rods", Structures, Volume 34, December 2021, Pages 2406-2414.

[6]. MohamedAdel, "Early damage detection of fatigue failure for RC deck slabs under wheel load moving test using image analysis with artificial intelligence", Engineering Structures, Volume 246, 1 November 2021, 113050.

[7]. AntonBogdanić, "Numerical and experimental investigation of anchor channels subjected to shear load in composite slabs with profiled steel decking", Engineering Structures, Volume 240, 1 August 2021, 112347.

[8]. DaXiang, "Fatigue behavior and failure mechanism of steel-concrete composite deck slabs with perforated ribs, Engineering Structures", Volume 250, 1 January 2022, 113410

[9]. FabricioBolina, "Thermal analysis of steel decking concrete slabs in case of fire", Fire Safety Journal, Volume 121, May 2021, 103295.

[10]. OuYi, "Performance of crumb rubber concrete composite-deck slabs in 4-point-bending, Journal of Building Engineering", Volume 40, August 2021, 102695.

[11]. Alex M.D.de Sousa, "Extended CSDT model for shear capacity assessments of bridge deck slabs, Engineering Structures", Volume 234, 1 May 2021, 111897. 
[12]. Rajai Z.Al-Rousan, "Nonlinear finite element analysis of full-scale concrete bridge deck slabs reinforced with FRP bars", Structures, Volume 27, October 2020, Pages 1820-1831.

[13]. P.Arezoomand Langarudi, "Numerical study of the behavior of bolted shear connectors in composite slabs with steel deck", Structures, Volume 26, August 2020, Pages 501-515.

[14]. Ying-JieZhu, "Novel design method for reinforced concrete decks in composite girders considering compressive membrane action", Engineering Structures, Volume 229, 15 February 2021, 111558.

[15]. YuZheng, "Investigation of the behaviour of SCC bridge deck slabs reinforced with BFRP bars under concentrated loads", Engineering Structures, Volume 171, 15 September 2018, Pages 500-515

\section{Cite this article as :}

Nikhil Agrawal, Dr. Rajeev Chandak, "DWT Based Deflection Optimization in Deck Slab with Free Vibration Analysis", International Journal of Scientific Research in Science and Technology (IJSRST), Online ISSN : 2395-602X, Print ISSN : 23956011, Volume 8 Issue 6, pp. 285-291, NovemberDecember 2021. Available at doi : https://doi.org/10.32628/IJSRST218627

Journal URL : https://ijsrst.com/IJSRST218627 